\title{
Reduction of peritoneal adhesion bands by mycophenolate mofetil (CellCept) and prednisolone in rats
}

\author{
Behnam Sanei, Mohsen Mahmoudieh, Parnian Shariati, Ehsan Zare Bidaki, \\ Mohsen Mahmoudieh, Hamid Talebzade, Hamid Reza Jafari
}

\begin{abstract}
Aims: The purpose of this study was to assess the efficacy of prednisolone and CellCept in decreasing postoperative adhesion band formation in rats. Methods: Sixty male rats were randomly divided into three equal groups. A standard midline incision was made on the abdomen of each rat, then $2 \mathrm{~mL}$ of $10 \%$ sterile solution Talc was injected into intraperitoneal cavity in order to induce adhesion. Group 1 served as control group, while group 2 received oral CellCept (40 $\mathrm{mg} / \mathrm{kg} / \mathrm{d})$ and group 3 received oral Prednisolone $(5 \mathrm{mg} / \mathrm{kg} / \mathrm{d})$ for 4 weeks. Results: The formation of adhesion bands in control group was significantly higher than the prednisolone and CellCept group $(p<0.001)$. The amount of adhesion bands in the second group was similar to the third one. Conclusion: Orally administered CellCept is as effective as oral prednisolone in declining chance of intraperitoneal adhesion band formation, although it causes fewer complications such as infection in rats.
\end{abstract}

Keywords: Adhesion band, Mycophenolate Mofetil (CellCept), Prednisolone

Behnam Sanei ${ }^{1}$, Mohsen Mahmoudieh ${ }^{1}$, Parnian Shariati ${ }^{2}$, Ehsan Zare Bidaki ${ }^{3}$, Hamid Talebzade ${ }^{2}$, Hamid Reza Jafari ${ }^{4}$

Affiliations: ${ }^{1}$ Assistant Professor, Department of Surgery, Isfahan University of Medical Sciences, Isfahan, Iran; ${ }^{2}$ Department of Surgery, Isfahan University of Medical Sciences, Isfahan, Iran; ${ }^{3}$ Department of Internal Medicine, Isfahan University of Medical Sciences, Isfahan, Iran; ${ }^{4}$ Medical Student, Isfahan University of Medical Sciences, Isfahan, Iran.

Corresponding Author: Dr. Parnian Shariati, Department of Surgery, Isfahan University of Medical Sciences, Isfahan, Iran; Email: p.shariati2000@gmail.com

Received: 04 April 2014

Accepted: 09 May 2014

Published: 29 July 2014

\section{How to cite this article}

Sanei B, Mahmoudieh M, Shariati P, Bidaki EZ, Talebzade H, Jafari HR. Reduction of peritoneal adhesion bands by mycophenolate mofetil (CellCept) and prednisolone in rats. Int $J$ Hepatobiliary Pancreat

Dis 2014;4:40-45.

Article ID: 100019IJHPDGN2014

$* * * * * * * * *$

doi:10.5348/ijhpd-2014-19-OA-7

\section{INTRODUCTION}

Peritoneal adhesions form pathological junctions between the omentum, small and large bowel, abdominal wall, and other intra-abdominal organs. These improper bonds vary from a thin layer of connective tissue to a thick fibrous bridge containing blood vessels and nerve tissue which thoroughly attach two organ surfaces [1-4].

Adhesion formation is a common complication of the abdominal surgery which happens in more than majority of patients after abdominal and colorectal surgeries $[4,5]$. Small bowel obstruction (most overriding one), persistent pelvic pain, ectopic pregnancy, and infertility are some illustration of adhesion complications [4, $6,7]$. Moreover, about $6 \%$ of all re-admissions are in the correlation with adhesion formation and require further surgical intervention which the burden of such surgical interventions is dramatically increased [4, 8-10]. Thus, patients' quality of life is unfortunately affected by adhesion-related problems. As anticipated, the high recurrence rate of small bowel adhesion-related obstruction followed by expensive medical management is a considerable issue in this matter $[4,11,12]$.

Recently, no convenient method is established in order to prevent adhesion formation or recurrence [13]. 
Further valid evidence and studies are necessary to reach a comprehensive understanding of the pathogenesis of adhesions at cellular and molecular level to streamline preventative and curative strategies and convert these theories into practice [14]. Recent studies claimed that three processes have a role in adhesion formation which are induced by trauma. First, the fibrinolytic and extracellular matrix degradation systems are ceased $[15,16]$. Then, cytokines and growth factor- $\beta$ (TGF- $\beta 1$ ), an important regulator of tissue fibrosis, develop an inflammatory reaction $[17,18]$. After that, blood supply to mesothelial cells and submesothelial fibroblasts are interrupted and hypoxia leads to increased production of hypoxia-induced factor-1 $\alpha \quad[19,20]$ and vascular endothelial growth factor. The aforementioned factors play a critical role in collagen formation and angiogenesis [21].

Open surgery has traumatic effects in correlation with the midline incision which gives access to the operated regions. As a matter of fact, abdominal open surgery can pose further postoperative challenges due to the factors such as tissue dehydration, ischemia owing to ligation and suturing, and bacterial contamination, in addition to surgical incision site extension, abdominal organ manipulation, and foreign bodies accumulation $[4,22]$. On the other hand, some authors claim that laparoscopy approach has little effect on postoperative complications such as adhesions, while others disagree $[4,7]$. Adhesion formation is initiated exactly after operation. On seventh day after operation, adhesion band stability is increased, and fibrinolysis process get started. Based on the inflammatory process of adhesion band formation, it comes to mind that applying systemic and local immune-suppressive drugs during this period can prevent this stage. Therefore, some clinical trials were conducted because of this hypothesis and the result of a variety of drugs, including steroids, non-selective and selective cyclooxygenase inhibitors, 3-hydroxy-3methylglutaryl-CoA reductase inhibitors (Statins), and tissue-plasminogen activator were inquired. However, still none of these meet the desired outcomes [23-31].

As previously mentioned, majority of patients suffering from recurrent bowel obstruction require multiple surgical intervention. Prophylactic medical interventions show the light of hope because surgical elimination of adhesion bands do not prevent the new adhesions. Fortunately, there is an interval between the initiation of adhesion formation and its solidification. This period may be an opportunity in order to exert preventive and prophylactic management to solve this surgical obstacle [10]. In association with recent studies, new immunosuppressive drugs act more properly in this issue, besides having fewer side effects.

The goal of this study was to investigate the effectiveness of CellCept and prednisolone in the process of preventing adhesions and compare them together.

\section{MATERIALS AND METHODS}

Sixty male rats of reproductive age, weighting 200300 grams selected in this study and were randomly divided into three equal groups. The animals were kept at standard pathogen free laboratory condition (temp: $20-24^{\circ} \mathrm{C}$, relative humidity; 12 hour light-dark cycle, fed with standard rat food and water). It is important to mention that no animal rights were infringed, and the procedure and handling of the animals were approved by our National Society of Medical Research and National Institution of Health.

Group 1: control group that received no drug

Group 2: received mycophenolate mofetil (CellCept)

Group 3: received prednisolone

According to this study design, in order to stimulate adhesion formation process by laparotomy, anesthesia was induced by acepromazine $(2.5 \mathrm{mg} / \mathrm{kg})$ and ketamin hydrochloride $(80 \mathrm{mg} / \mathrm{kg})$ in rats, then midline abdominal hair was shaved. After that, $1 \mathrm{~cm}$ incision was made on midline of the abdominal wall and $2 \mathrm{~mL}$ of $10 \%$ talc was injected into the abdominal cavity. At the end, the peritoneum and abdominal wall was sutured and the rats were examined daily for wound complication.

The first group received no drug. Group 2 received oral CellCept (40 mg/kg/day) and group 3 received oral prednisolone $(5 \mathrm{mg} / \mathrm{kg} /$ day $)$, which were dissolved in distilled water and administered by a long metal oral gavage. All rats received medication for 4 weeks and by the end of fourth week, the rats were put to sleep. Their abdominal cavities were explored, and number and degree of adhesion bands were recorded according to the peritoneal adhesion index (PAI) classification by score of o to 4 (Table 1).

Statistical analysis was performed by using the SPSS 20 software. The final outcome was analyzed by $t$-test and ANOVA test. Statistical significant was defined as $\mathrm{p} \leq 0.5$.

Table 1: Distribution of the number of bands stuck in the three groups.

\begin{tabular}{|c|c|c|c|c|c|c|}
\hline \multirow{2}{*}{ Groups } & \multicolumn{2}{|c|}{ Control group } & \multicolumn{2}{|c|}{ CellCept } & \multicolumn{2}{|c|}{ Prednisolone } \\
\hline & $\mathrm{n}$ & $\%$ & $\mathrm{n}$ & $\%$ & $\mathrm{n}$ & $\%$ \\
\hline O & o & o & 2 & 10 & 5 & 25 \\
\hline 1 & 2 & 10 & 14 & 70 & 8 & 40 \\
\hline 2 & 5 & 25 & 4 & 20 & 6 & 20 \\
\hline 3 & 12 & 60 & 0 & O & 1 & 5 \\
\hline 4 & 1 & 5 & O & o & 0 & o \\
\hline total & 20 & 100 & 20 & 100 & 20 & 100 \\
\hline
\end{tabular}

$\mathrm{p}<0.001$ 


\section{RESULTS}

In this study, 60 rats were selected and randomly divided into three groups of 20 rats. In the first group, the control group received no drug. Group 2 and group 3 CellCept and Prednisolone were administered, respectively.

In Table 1 and Figure 1, frequency of adhesion bands in the three groups are shown. Fisher's exact test on the data showed the amount of frequency adhesive bands are significantly different $(p<0.001)$ between the groups. Based on the test, the frequency of adhesive bands between the control and Cellcept group was different ( $p$ $<$ o.001). Furthermore, the prednisolone group result was different from control group $(p<0.001)$. On the contrary, between the two groups receiving CellCept and prednisolone, there was no difference $(p=0.1)$. The total number of adhesive band formation was 53 cases, CellCept group included 16 cases and prednisolone group included 15 cases. The fitness test for all bands, the adhesion in the three groups was statistically significant $(p<0.001)$. The average amount of adhesive band formation in the control group was 75/o \pm 2.6 , in CellCept group was 49/o \pm 1 , and in prednisolone group was $88 / 0 \pm 1.15$ in each rat. According to ANOVA test, the mean number of adhesive band formation in three groups was significant ( $p<$ o.001). LSD pursuit tests also showed that the average amount of adhesive band in control group in comparison to the other two groups was statistically significant, however, no difference was observed between the two groups of CellCept and prednisone $(\mathrm{p}=0.53)$.

In Table 2, the frequency of complications in the three groups is given. During the study, eight rats developed wound infection in which one $(5 \%)$ rat was in the control group (abdominal wall wound infection), two (10\%) rats were on CellCept and 5 (25\%) rats were in the prednisolone group (infection of the lining of the abdomen). But according to Fisher's exact test, wound infection in the three groups were different $(p=0.25)$. Notably, in the group receiving prednisolone, abdominal hair did not grow well after shaving in comparison to other groups.

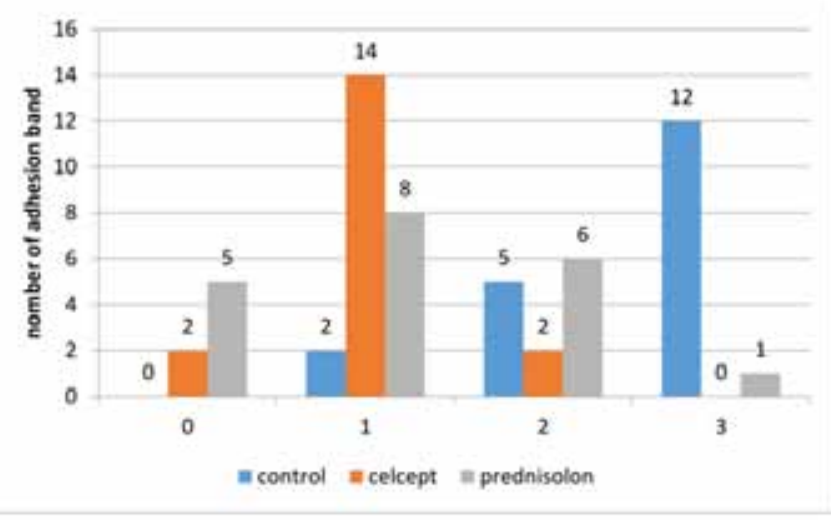

Figure 1: The absolute frequency of adhesion in three groups.

\section{DISCUSSION}

Some patients need multiple surgeries due to the frequent adhesions. Nevertheless, the macroscopic separation of adhesion formation does not prevent future development of adhesion bands. In addition, the band formation which is because of previous surgical procedures may finally cause small bowel obstruction. In this study, we demonstrated that the incidence of adhesion bands in CellCept and prednisolone groups was less than control group. Moreover, the frequency of wound infection in CellCept group was less than prednisolone group. The probable cause for this inequality is that CellCept has a biochemical targeted impression on immune system in comparison to prednisolone.

Mycophenolate mofetil (CellCept), known antiinflammatory and immunosuppressive agent, has little effect on B cell and T cell. Presumably, this drug decreases adhesion formation prevalence by ceasing inflammatory process, which is an essential component of this process. Formation of adhesions is the final consequence of the engagement between deposition of fibrinous exudates and lysis of the fibrin by fibrinolytic system of mesothelial cells. Moreover, foreign materials in the abdominal cavity may lead to formation of inflammatory reaction in the peritoneal wall $[4,32]$.

Table 2: Distribution of complications in three groups

\begin{tabular}{|c|c|c|c|c|c|c|c|c|}
\hline \multirow[t]{2}{*}{ Complication } & \multirow[t]{2}{*}{ Groups Level } & \multicolumn{2}{|c|}{ Control group } & \multicolumn{2}{|c|}{ Cell Cept } & \multicolumn{2}{|c|}{ Prednisolone } & \multirow[t]{2}{*}{$\mathbf{p}$} \\
\hline & & $\mathbf{n}$ & $\%$ & $\mathbf{n}$ & $\%$ & $\mathbf{n}$ & $\%$ & \\
\hline \multirow[t]{2}{*}{ infection } & Yes & 1 & 5 & 2 & 10 & 5 & 25 & 0.25 \\
\hline & No & 19 & 95 & 18 & 90 & 15 & 75 & \\
\hline \multirow[t]{2}{*}{ death } & Yes & o & o & 1 & $5 \cdot 3$ & 1 & $5 \cdot 3$ & 0.99 \\
\hline & No & 20 & 100 & 19 & 94.7 & 19 & 94.7 & \\
\hline
\end{tabular}


Multiple drugs have been used in several animal studies with the purpose of prophylactic management of adhesion band formation. In some recent studies, it was mentioned that prednisolone and CellCept are used above usual dosage and the results were compared to each other. Various strategies have been devised to reduce the incidence of peritoneal adhesions; nonetheless, partial achievement has been gained up to now [33]. One of them was removal of fibrinous exudates by peritoneal lavage [34, 35]. The rest included anti-inflammatory and anti-coagulation agents [36] by administration of dexamethasone and aprotinin [37] and other drugs such as chitosan [38], mitomycin [39], rosiglitazone [40], Vitamin E [41], colchicine and D. penicillamin infleximab [42]. According to a study, the leukocytes count and the prevalence of postoperative adhesion formation in rats were declined by administration of intraperitoneal estrogen [43].

Solid organ transplantation rate has increased globally since the first successful human kidney in 1954 . Organ transplantation has become an optimal means in the treatment of some diseases, such as liver or kidney failure. In the process of organ transplantation, there are two phases of immunosuppressive approach. First step, the administration of methylprednisolone, at a dose of approximately $3 \mathrm{~g}$, is equally as effective as high dose of prednisolone. The second step is the maintenance therapy which is consisted of a combination of two immunosuppressive drugs such as CellCept, tacrolimus, and prednisolone $[44,45]$. In spite of the fact that all transplant candidates use high level of immunosuppressive agents, the infection after organ transplantation is not considered as a main obstacle to transplant operation. The result of this study showed that Cellcept has generally more promising outcome. However, both Cellcept and prednisolone may reduce adhesion band occurrence. Therefore, short-term consumption of a low dose immunosuppressive drug in patients who have gone under several surgeries due to bowel obstruction of adhesions may be used as a strategy in prophylaxis. Further human studies are required to discover immunosuppressive drugs with higher efficacy and lower risks.

\section{CONCLUSION}

This study demonstrated that immunosuppressive drugs are effective in preventing adhesion formation which this hypothesis is in parallel with previous studies. By our animal study, we realized that CellCept is as effective as prednisolone in the prevention of adhesion band formation, besides developing fewer side effects in rats. Due to the fact that Cellcept has fewer side effects, it may be useful to prescribe immunosuppressive drugs in patients who have several surgeries because of adhesions. But, extensive reliable human studies are necessary to lighten the dark spots in this route.

\section{Author Contributions}

Behnam Sanei - Substantial contributions to conception and design, Acquisition of data, Analysis and interpretation of data, Drafting the article, Revising it critically for important intellectual content, Final approval of the version to be published

Mohsen Mahmoudieh - Analysis and interpretation of data, Revising it critically for important intellectual content, Final approval of the version to be published

Parnian Shariati - Analysis and interpretation of data, Revising it critically for important intellectual content, Final approval of the version to be published

Ehsan Zare Bidaki - Analysis and interpretation of data, Revising it critically for important intellectual content, Final approval of the version to be published

Hamid Talebzade - Analysis and interpretation of data, Revising it critically for important intellectual content, Final approval of the version to be published

Hamid Reza Jafari - Analysis and interpretation of data, Revising it critically for important intellectual content, Final approval of the version to be published

\section{Guarantor}

The corresponding author is the guarantor of submission.

\section{Conflict of Interest}

Authors declare no conflict of interest.

\section{Copyright}

(C) 2014 Behnam Sanei et al. This article is distributed under the terms of Creative Commons Attribution License which permits unrestricted use, distribution and reproduction in any medium provided the original author(s) and original publisher are properly credited. Please see the copyright policy on the journal website for more information.

\section{REFERENCES}

1. Diamond MP, Freeman ML. Clinical implications of postsurgical adhesions. Hum Reprod Update 2001;7(6):567-6.

2. Arung W, Meurisse M, Detry O. Pathophysiology and prevention of postoperative peritoneal adhesions. World journal of gastroenterology 2011;17(41):45453 .

3. Sulaiman H, Gabella G, Davis MSc C, et al. Presence and distribution of sensory nerve fibers in human peritoneal adhesions. Ann Surg 2001;234(2):256-1.

4. Coccolini F, Ansaloni L, Manfredi R, et al. Peritoneal adhesion index (PAI): Proposal of a score for the "ignored iceberg" of medicine and surgery. World Journal of Emergency Surgery 2013;8(1):6.

5. Menzies D, Ellis H. Intestinal obstruction from adhesions--how big is the problem? Annals of the Royal College of Surgeons of England 1990;72(1):603 . 
6. Vrijland WW, Jeekel J, van Geldorp HJ, Swank DJ, Bonjer HJ. Abdominal adhesions: Intestinal obstruction, pain, and infertility. Surg Endosc 2003;17(7):1017-22.

7. Pismensky SV, Kalzhanov ZR, Eliseeva MY, Kosmas IP, Mynbaev OA. Severe inflammatory reaction induced by peritoneal trauma is the key driving mechanism of postoperative adhesion formation. BMC surgery 2011;11:30.

8. Ellis H, Moran BJ, Thompson JN, et al. Adhesionrelated hospital readmissions after abdominal and pelvic surgery: A retrospective cohort study. The Lancet 1999;353(9163):1476-80.

9. Van Der Krabben AA, Dijkstra FR, Nieuwenhuijzen M, Reijnen MM, Schaapveld M, Van Goor $\mathrm{H}$. Morbidity and mortality of inadvertent enterotomy during adhesiotomy. British Journal of Surgery 2000;87(4):467-1.

10. van Goor H. Consequences and complications of peritoneal adhesions. Colorectal Dis 2007;9(Suppl 2):25-34.

11. Duron JJ, Silva NJ, du Montcel ST, et al. Adhesive postoperative small bowel obstruction: Incidence and risk factors of recurrence after surgical treatment: A multicenter prospective study. Ann Surg 2006;244(5):750-7.

12. Tingstedt B, Isaksson J, Andersson R. Long-term follow-up and cost analysis following surgery for small bowel obstruction caused by intra-abdominal adhesions. Br J Surg 2007;94(6):743-8.

13. Wiseman DM, Trout JR, Diamond MP. The rates of adhesion development and the effects of crystalloid solutions on adhesion development in pelvic surgery. Fertility and Sterility 1998;70(4):702-11.

14. Cheong YC, Laird SM, Li TC, Shelton JB, Ledger WL, Cooke ID. Peritoneal healing and adhesion formation/ reformation. Hum Reprod Update 2001;7(6):556-6.

15. Holmdahl L, Eriksson E, Eriksson BI, Risberg B. Depression of peritoneal fibrinolysis during operation is a local response to trauma. Surgery 1998;123(5):539-44.

16. Ivarsson $\mathrm{M}$, Bergström $\mathrm{M}$, Eriksson $\mathrm{E}$, Risberg B, Holmdahl L. Tissue markers as predictors of postoperative adhesions. Br J Surg 1998;85(11):15494.

17. Holmdahl L, Kotseos K, Bergström M, Falk P, Ivarsson ML, Chegini N. Overproduction of transforming growth factorbeta1 (TGF-beta1) is associated with adhesion formation and peritoneal fibrinolytic impairment. Surgery 2001;129(5):626-32.

18. Chegini N, Kotseos K, Zhao Y, et al. Differential expression of TGF-beta1 and TGF-beta3 in serosal tissues of human intraperitoneal organs and peritoneal adhesions. Hum Reprod 2001;16(6):1291300.

19. Cheong YC, Shelton JB, Laird SM, Li TC, Ledger WL, Cooke ID. Peritoneal fluid concentrations of matrix metalloproteinase- 9 , tissue inhibitor of metalloproteinase-1, and transforming growth factorbeta in women with pelvic adhesions. Fertility and Sterility 2003;79(5):1168-75.

20. Molinas CR, Campo R, Elkelani OA, Binda MM, Carmelie P, Koninckx PR. Role of hypoxia inducible factors 1alpha and 2alpha in basal adhesion formation and in carbon dioxide pneumoperitoneum-enhanced adhesion formation after laparoscopic surgery in transgenic mice. Fertility and Sterility 2003;80(Suppl 2):795-802.

21. Segura T, Schmokel H, Hubbell JA. RNA interference targeting hypoxia inducible factor 1alpha reduces post-operative adhesions in rats. $J$ Surg Res 2007;141(2):162-70.

22. Cahill RA, Wang JH, Soohkai S, Redmond HP. Mast cells facilitate local VEGF release as an early event in the pathogenesis of postoperative peritoneal adhesions. Surgery 2006;140(1):108-12.

23. Sileri P, Sthory R, McVeigh E, et al. Adhesions are Common and Costly after Open Pouch Surgery. Journal of Gastrointestinal Surgery 2008;12(7):123945.

24. Avsar FM, Sahin M, Aksoy F, et al. Effects of diphenhydramine $\mathrm{HCl}$ and methylprednisolone in the prevention of abdominal adhesions. Am J Surg 2001;181(6):512-5.

25. Sahin M, Cakir M, Avsar FM, Tekin A, Kucukkartallar T, Akoz M. The effects of anti-adhesion materials in preventing postoperative adhesion in abdominal cavity (anti-adhesion materials for postoperative adhesions). Inflammation 2007;30(6):244-9.

26. Muzii L, Marana R, Brunetti L, Margutti F, Vacca M, Mancuso S. Postoperative adhesion prevention with low-dose aspirin: effect through the selective inhibition of thromboxane production. Hum Reprod 1998;13(6):1486-9.

27. Oh SH, Kim JK, Song KS, et al. Prevention of postsurgical tissue adhesion by anti-inflammatory drug-loaded pluronic mixtures with sol-gel transition behavior. J Biomed Mater Res A 2005;72(3):306-16.

28. Rodgers KE, Johns DB, Girgis W, diZerega GS. Prevention of adhesion formation with intraperitoneal administration of tolmetin and hyaluronic acid. J Invest Surg 1997;10(6):367-3.

29. Aldemir M, Oztürk $H$, Erten $C$, Büyükbayram $H$. The preventive effect of rofecoxib in postoperative Intraperitoneal adhesions. Acta Chir Beig 2004;104(1):97-100.

30. Dörr PJ, Vemer HM, Brommer EJ, Willemsen WN, Veldhuizen RW, Rolland R. Prevention of postoperative adhesions by tissuetype plasminogen activator (t-PA) in the rabbit. Eur J Obstet Gynecol Reprod Biol 1990;37(3):287-91.

31. Kutlay J, Ozer Y, Isik B, Kargici H. Comparative effectiveness of several agents for preventing postoperative adhesions. World J Surg 2004;28(7):662-5.

32. van den Tol MP, Haverlag R, van Rossen ME, Bonthuis F, Marquet RL, Jeekel J. Glove Powder Promotes Adhesion formation and Facilitates Tumour Cell Adhesion and Growth. Br J Surg 2001;88(9):125863.

33. Nikeghbalian S, Atefi S, Kazemi K, Roshan N, Tanideh $\mathrm{N}$, Jalaeian H. Effect of oral D-penicillamine vs. colchicine on experimentally induced peritoneal adhesions in rats. Fertility and Sterility 2007;88(4 Suppl):1187-9.

34. Yagmurlu A, Barlas M, Gursel I, Gokcora IH. Reduction of surgery induced peritoneal adhesion by continuous release of streptokinase from a drug delivery system. Eur Surg Res 2003;35(1):46-9. 
35. Cavallari N, Polistena A, Cavallaro A. Inability of university of Wisconsin solution to reduce postoperative peritoneal adhesion in rat. Eur J Surg 2000;166(8):650-3.

36. Ozgün H, Cevikel MH, Kozaci LD, Sakarya S. Lexipafant inhibits postsurgical adhesion formation. The Journal of Surgical Research 2002;103(2):141-5.

37. Kucukozkan T, Ersoy B, Uygur D, Gundogdu C. Prevention of adhesion by sodium chromoglycate, dexamethazone, salineand aprotinin after pelvic surgery. ANZ J Surg 2004;74(12):1111-5.

38. Zhang ZL, Xu SW, Zhou XL. Prevention effects of chitosan on peritoneal adhesion in rats. World journal of gastroenterology 2006;12(28):4572-7.

39. Cubukçu A, Alponat A, Gönüllü NN, Ozkan S, Erçin C. An experimental study evaluating the effect of Mitomycin $\mathrm{C}$ on the prevention of postoperative intraabdominal adhesions. J Surg Res 2001;96(2):163-6.

40. Demirturk F, Aytan H, Caliskan A, et al. The effect of rosiglitazone in the prevention of intra-abdominal adhesion formation in a rat uterine horn model. Hum Reprod 2006;21(11):3008-13.

41. Yetkin G, Uludag M, Citgez B, Karakoc S, Polat N, Kabukcuoglu F. Prevention of peritoneal adhesions by intraperitoneal administration of vitamin $\mathrm{E}$ and human amniotic membrane. Int $\mathrm{J}$ Surg 2009;7(6):561-5.

42. Kurukahvecioglu O, Koksal H, Gulbahar O, et al. Infliximab "TNF-alpha antagonist" decreases intraabdominal adhesions. Saudi Med J 2007;28(12):1830-5.

43. Bozkurt S, Yuzbasioglu MF, Bulbuloglu E, Gul M, Kale IT. Prevention of postoperative peritoneal adhesions by administration of estrogen. J Invest Surg 2009;22(4):263-7.

44. Kahan BD. Individuality: The barrier to optimal immunosuppression. Nat Rev Immunol 2003;3(10):831-8.

45. Kasiske BL, Zeier MG, Craig JC, et al. KDIGO clinical practice guideline for the care of kidney transplant recipients. Am J Transplant 2009;9(Suppl 3):S1-155.
Access full text article on other devices

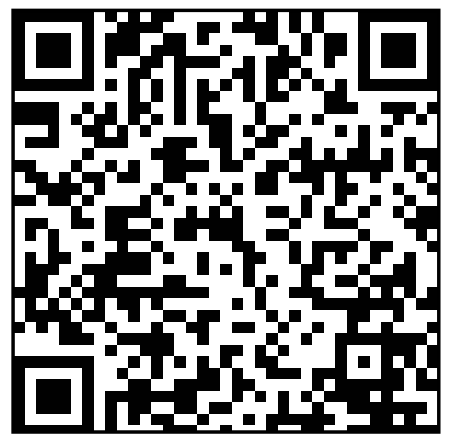

Access PDF of article on other devices

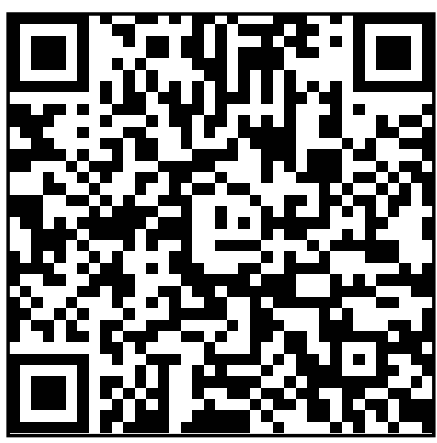

